\title{
CRISIS Y DESAFÍOS PARA LAS HUMANIDADES EN EL MUNDO ACTUAL
}

\section{Camila Gonzalez}

\section{Fecha: 10 de octubre de 2019}

\section{Resumen}

En todos esos esfuerzos, sin embargo, no se ha hecho una pregunta simple de supervivencia: si las humanidades están en crisis, ¿qué estamos haciendo en las humanidades? Esa es una pregunta que lleva a otras consultas fundamentales. ¿Qué es esto en lo que estamos? ¿Cómo llegamos allí en primer lugar? ¿Qué está en juego en quedarse? Para cerrar la crisis de las humanidades, necesitamos poner las humanidades en una historia que pueda darle un cierre. Eso significa identificar primero sus orígenes. ¿Qué edad tiene la etiqueta "humanidades"? ¿Por qué se aplicó ya qué? ¿Qué comparte con sus términos hermanos, ciencias y ciencias sociales? Las respuestas a estas preguntas son lo suficientemente sorprendentes como para plantear otras: ¿Qué podría pasar si lo quitamos? Pensar en eso es pensar en la importancia que tiene para los pueblos su lenguaje natural, su historia, su poesía y su canto. Ese pensamiento es más profundo, creo, cuando está impregnado de las humanidades, incluso cuando las trasciende, como hace la antropología, por ejemplo.

Palabras clave: Humanidades, Historia, Lenguaje natural.

\begin{abstract}
In all these efforts, however, no simple question of survival has been asked: if the humanities are in crisis, what are we doing in the humanities? That is a question that leads to other fundamental questions: What is this that we are in? How did we get there in the first place? What is at stake in staying? To close the crisis in the humanities, we need to put the humanities into a story that can bring closure. That means identifying their origins first. How old is the label "humanities"? Why did it apply already? What does it share with its sister terms, science and social science? The answers to these questions are surprising enough to raise others: What could happen if we remove it? To think about that is to think about the importance to people of their natural language, their history, their poetry and their song.
\end{abstract}


Keywords: Humanities, History, Natural language.

\section{Introducción}

Las principales respuestas han sido culpar o jugar. Las personas que juegan el juego de la culpa se han vuelto contra los demás, insistiendo en lo que los presidentes, decanos, estudiantes con vocación de carrera y el neoliberalismo nos han estado haciendo "a nosotros". Los manitas han probado modestas formas de superación personal. En los Estados Unidos, incluyen departamentos de investigación en estudios literarios que están agregando pistas de escritura creativa a sus especialidades para reforzar los números.

En todos esos esfuerzos, sin embargo, no se ha hecho una pregunta simple de supervivencia: si las humanidades están en crisis, ¿qué estamos haciendo en las humanidades? Esa es una pregunta que lleva a otras consultas fundamentales. ¿Qué es esto en lo que estamos? ¿Cómo llegamos allí en primer lugar? ¿Qué está en juego en quedarse? ¿Podríamos irnos?

Para cerrar la crisis de las humanidades, necesitamos poner las humanidades en una historia que pueda darle un cierre. Eso significa identificar primero sus orígenes. ¿Qué edad tiene la etiqueta "humanidades"? ¿Por qué se aplicó ya qué? ¿Qué comparte con sus términos hermanos, ciencias y ciencias sociales? Las respuestas a estas preguntas son lo suficientemente sorprendentes como para plantear otras: ¿Qué podría pasar si lo quitamos?

Primera sorpresa: lejos de ser la empresa antigua y venerada a menudo representada por muchas personas que defienden las humanidades, el término adquirió su principal 
significado moderno hace menos de 200 años. "La rama del saber”, dice el Oxford English Dictionary con una primera cita de 1855 , "preocupada por la cultura humana; las materias académicas que componen colectivamente esta rama del saber, como historia, literatura, lenguas antiguas y modernas, derecho, filosofía, arte y música ”. Esa formulación era una mezcla genuinamente nueva de dos conceptos dinámicos: humanidades y cultura.

Solo unas décadas antes, "humanidades" había significado algo muy diferente. A lo largo del siglo XVIII, se utilizó para distinguir las lenguas clásicas de las modernas y la secular en contraposición al aprendizaje divino. La "cultura" estaba aún más en proceso de cambio; en su sentido moderno de "una forma de vida particular" y de "lo mejor que se ha pensado y escrito", era un término nuevo que surgió por primera vez en el idioma a principios del siglo XIX. ${ }^{1}$

Segunda sorpresa: cuando las disciplinas modernas surgieron por primera vez de la Ilustración europea - la Enciclopedia Británica de 1797 las llamó las nuevas " partes separadas del conocimiento" - no eran partes de una entidad preexistente llamada las "humanidades". De hecho, las tres categorías estándar de hoy - las "ciencias " y las “ ciencias sociales ", así como las "humanidades" - no fueron clasificaciones de conocimiento primarias sino secundarias impuestas a las disciplinas entre 1830 y 1860.

Pensar en eso es pensar en la importancia que tiene para los pueblos su lenguaje natural, su historia, su poesía y su canto. Ese pensamiento es más profundo, creo, cuando está impregnado de las humanidades, incluso cuando las trasciende, como hace la antropología, por ejemplo. Una sensibilidad alimentada por las humanidades permitió al gran antropólogo australiano WH Stanner ver en la cultura de los pueblos indígenas de

\footnotetext{
${ }^{1}$ Reale, Giovanni, Dario Antiseri, and Juan Andrés Iglesias. Historia del pensamiento filosófico y científico. Vol. 1. Madrid: Herder, 1988.
} 
Australia "toda la belleza del canto, la mímica, la danza y el arte de que son capaces los seres humanos"2.

El descubrimiento por parte de muchos intelectuales occidentales de la profundidad moral o espiritual en prácticas y creencias que anteriormente parecían expresar solo las supersticiones de salvajes científicamente atrasados es un logro de la segunda mitad del siglo XX por el que debemos agradecer. Ascendió a una nueva capacidad para ver (como Stanner vio) en las culturas negras una respuesta cada vez más profunda a los hechos definitorios de la condición humana --nuestra mortalidad, nuestra sexualidad, nuestra vulnerabilidad a la desgracia-- y, por lo tanto, verlas como culturas de las cuales Occidente podría aprender.

Ahora cambiaré un poco el rumbo porque quiero hablar de Sócrates. O, más exactamente, hablaré del personaje de Sócrates en los diálogos del gran filósofo-poeta Platón. Platón fue discípulo del histórico Sócrates, el filósofo que vivió en Atenas hace más de 2500 años. Estaba preocupado por lo que llamó "la antigua disputa entre poesía y filosofía". 3 Mucha gente piensa que Platón creía que había resuelto esa disputa a favor de la filosofía. En República, prohibió a los poetas del estado ideal. Pero si eso expresara su opinión final y sin problemas, no podría haber producido las grandes obras de arte que son sus diálogos y habernos dado a Sócrates, plenamente realizado como personaje más que como portavoz de argumentos filosóficos. Es el personaje que ha perseguido la imaginación moral y política occidental, la reflexión sobre lo que significa vivir la vida de la mente y, de manera más general, sobre por qué debemos luchar por la lucidez sobre los significados de lo que hacemos, pensamos y sentimos.

\footnotetext{
${ }^{2}$ Edwards, William Howell. Traditional Aboriginal Society. Macmillan Co of Australia, 1998.

${ }^{3}$ Zubiri, Xavier. Sócrates y la sabiduría griega. Vol. 2. Ediciones Escorial, 1940.
} 
Pertenezco a un grupo relativamente pequeño de filósofos que creen que la filosofía moral y política se vuelve estéril cuando no se comprometen creativamente con el arte, especialmente con la literatura. ${ }^{4}$ Tanto la forma de mi trabajo como, de hecho, inseparablemente de su contenido, ha expresado esa creencia. El filósofo inglés Roger Scruton describió El perro del filósofo como un experimento de filosofía narrativa. Lo mismo podría decirse de After Romulus. Pero aunque he enfatizado en mi trabajo académico y en otros trabajos, y muchas veces en foros más públicos, que la filosofía se empobrece cuando su concepción de lo que es pensar con rigor no incluye una sensibilidad alimentada por el arte, también he enfatizado que el arte habla. para nosotros sólo porque se basa en el trasfondo de un entendimiento común. ${ }^{5}$

Evidentemente, las disciplinas discursivas de las humanidades contribuyen a ese entendimiento común. Igual de importante, juegan un papel indispensable a la hora de aclarar su carácter conceptual. Y son las humanidades, reflexionando críticamente sobre el Holocausto y las brutalidades del colonialismo, las que han sondeado, con un escepticismo serio, la suposición de que las humanidades humanizarían a quienes las estudian, o incluso los harían relativamente decentes.

Quizás ya se esté preguntando por qué le hablaría de un filósofo que murió hace 2500 años. Podrías pensar que el hecho de que se me ocurriera hacerlo es un ejemplo de la esterilidad de las humanidades, evidencia, de hecho, de que un graffitista tenía razón cuando escribía sobre los rollos de papel en los baños de hombres de la unión de este. universidad: "Grados en Humanidades. Siéntete libre de tomar uno ".

\footnotetext{
${ }^{4}$ Marchena, José. Lecciones de filosofía moral y elocuencia, ó coleccion de los trozos mas selectos de poesía, elocuencia, historia, religion, y filosofía moral y política, de los mejores autores castellanos. Vol. 1. Imprenta de Don Pedro Beaume, 1820.

${ }^{5}$ Scruton, Roger. The meaning of conservatism. Harmondsworth: Penguin Books, 1980.
} 
Pero para comprender la mayoría de las disciplinas de las humanidades, es necesario saber que su historia no es "solo historia". Los estudiosos de las humanidades, ciertamente los filósofos, se involucran críticamente con pensadores del pasado tan distantes de nosotros en el tiempo como los antiguos griegos, y se nutren de ellos. Esto tiene dos grandes beneficios. Uno es un tesoro. ${ }^{6}$

En primer lugar, el compromiso reflexivo con grandes pensadores y artistas del pasado le permite a uno vivir con alegría, porque se le da tanto al amor, en un presente extenso y continuo. Esto, mucho más que las trampas de una carrera académica razonablemente exitosa, me hace sentir diferente de muchos amigos que no han tenido el beneficio de mucha educación. Platón es mi compañero. También lo son Descartes y Kant, por nombrar sólo algunos grandes filósofos. Lo mismo ocurre con Esquilo, Shakespeare, Dostoievski y Bach. Y, por supuesto, hay otros. No podría imaginar mi vida sin ellos.

En segundo lugar, el compromiso crítico con el pasado nos ayuda a establecer el tipo de distancia con el presente que es necesaria si queremos siquiera intentar seriamente, sin autoengañarnos, resistirnos a convertirnos en meros hijos de nuestro tiempo, en el sentido peyorativo de esa expresión. . Existimos en el presente y, con suerte, podemos amar el mundo en el que nacimos, pero el presente puede ser tiránico a menos que nuestra conciencia de él se extienda mucho hacia el pasado. Podemos soñar con el futuro y esos sueños pueden sostener nuestras luchas por un mundo mejor, pero el futuro no existe y nadie sabe cómo será. No puede nutrirnos como solo lo puede hacer algo real. ${ }^{7}$

\footnotetext{
${ }^{6}$ Tutor Sánchez, Joaquín Darío. «DIVULGACIÓN Y FORMACIÓN EN NANOTECNOLOGÍA: UN PUENTE HACIA LA BIOÉTICA». Escritos 24, 53 (2016):483-506. https://doi.org/10.18566/escr.v24n53.a12 ${ }^{7}$ Vinolo, Stéphane. «¿QUÉ MÁS DA? - LA ESTÉTICA EN JEAN-LUC MARION». Escritos 25, 54 (2017):197-220. https://doi.org/10.18566/escr.v25n54.a09
} 
Los dictadores lo saben, por eso reescriben la historia para adaptarla a sus fines políticos y niegan a sus súbditos el acceso independiente a su pasado. Lo hacen porque saben que la resistencia a su gobierno se marchitará a menos que la esperanza se alimente de un acceso confiable al pasado. Las personas que luchan contra la opresión necesitan saber que sus ideales no son meros sueños, que se han inspirado, al menos en parte, por algo real a lo que la sobriedad les exige responder.

En lugar de alienarnos de los tiempos en los que nacimos, el pasado puede brindarnos un amor eterno por el mundo que nos protegerá del cinismo si tenemos la desgracia de vivir en circunstancias en las que la desilusión parece ser la única respuesta veraz. A veces la gente vive en tiempos oscuros.

En el diálogo de Platón, Gorgias, Sócrates dice que "no hay nada más importante en la juventud o la vejez que discutir cómo se debe vivir". Tenga en cuenta que él dice que es importante discutir esto en lugar de solo pensar en ello. Algunas personas piensan que es una tontería y una autocomplacencia. Lo importante es seguir adelante con la vida: hay que ser práctico para sobrevivir en este mundo, dirían. Pero a menudo, cuando ocurre la desgracia, cuando, por ejemplo, se les dice que les queda poco tiempo de vida, o cuando alguien querido sufre o muere, las mismas personas reevalúan lo que es más importante para ellos. ${ }^{8}$

Todo el mundo sabe esto. Pero, por supuesto, a menudo lo sabemos solo en nuestra cabeza, e incluso entonces solo en la parte superior de nuestra cabeza, en lugar de en nuestros huesos. ${ }^{9}$ Y si llegamos a entenderlo en nuestra cabeza y en nuestros huesos

\footnotetext{
${ }^{8}$ Gómez, Patricio Peñalver. Márgenes de Platón: La estructura dialéctica del diálogo y la idea de exterioridad. EDITUM, 1986.

${ }^{9}$ Sanhueza, Keti. "Jesucristo, prototipo de justicia y martirio, en favor de los pobres y marginados." Cuestiones Teológicas, 43, 99 (2016): 175-197. https://doi.org/10.18566/cueteo.v43n99.a08
} 
cuando llega la desgracia, somos propensos a olvidarlo cuando nos recuperamos. Ésta es una de las razones por las que Platón dice que los filósofos, con lo que se refiere a los amantes de la sabiduría, o para decirlo de manera menos portentosa, aquellos que quieren ser lúcidos sobre lo que realmente importa como distinto de lo que sólo parece importar, se aferran al recuerdo de lo que habían conocido una vez.

\section{REFERENCIAS}

Dulles, Avery. A History of Apologetics (Ignatius Press, 2005).

Dussel, Enrique. Teología de la Liberación: Un panorama de su desarrollo (Potrerrillo, 1995).

Edwards, William Howell. Traditional Aboriginal Society. Macmillan Co of Australia, 1998.

Illanes, José Luis y Josep-Ignasi Saranyana, Historia de la Teología, Biblioteca de Autores Cristianos 2002.

Gómez, Patricio Peñalver. Márgenes de Platón: La estructura dialéctica del diálogo y la idea de exterioridad. EDITUM, 1986.

Lois, Julio. Teología de la liberación: opción por los pobres. Vol. 1. (IEPALA Editorial, 1986).

Marchena, José. Lecciones de filosofía moral y elocuencia, ó coleccion de los trozos mas selectos de poesía, elocuencia, historia, religion, y filosofía moral y política, de los mejores autores castellanos. Vol. 1. Imprenta de Don Pedro Beaume, 1820.

Pérez Prieto, Victorino. "Los orígenes de la Teología de la liberación en Colombia: Richard Shaull, camilo torres, Rafael Ávila, "Golconda", sacerdotes para américa latina, cristianos por el socialismo y comunidades eclesiales de base." Cuestiones Teológicas, 43, 99 (2016): 73-108.

https://doi.org/10.18566/cueteo.v43n99.a04 
Pérez Prieto, Victorino. "Los orígenes de la Teología de la liberación en Colombia: Richard Shaull, camilo torres, Rafael Ávila, "Golconda", sacerdotes para américa latina, cristianos por el socialismo y comunidades eclesiales de base." Cuestiones Teológicas, 43, 99 (2016): 73-108. https://doi.org/10.18566/cueteo.v43n99.a04

Reale, Giovanni, Dario Antiseri, and Juan Andrés Iglesias. Historia del pensamiento filosófico y científico. Vol. 1. Madrid: Herder, 1988.

Sanhueza, Keti. "Jesucristo, prototipo de justicia y martirio, en favor de los pobres y marginados." Cuestiones Teológicas, 43, 99 (2016): 175-197. https://doi.org/10.18566/cueteo.v43n99.a08

Scruton, Roger. The meaning of conservatism. Harmondsworth: Penguin Books, 1980.

Tutor Sánchez, Joaquín Darío. «DIVULGACIÓN Y FORMACIÓN EN NANOTECNOLOGIAA: UN PUENTE HACIA LA BIOÉTICA». Escritos 24, 53 (2016):483-506. https://doi.org/10.18566/escr.v24n53.a12

Vinolo, Stéphane. «¿QUÉ MÁS DA? - LA ESTÉTICA EN JEAN-LUC MARION». Escritos 25, $54 \quad$ (2017):197-220. https://doi.org/10.18566/escr.v25n54.a09

Zubiri, Xavier. Sócrates y la sabiduría griega. Vol. 2. Ediciones Escorial, 1940. 